\title{
¿QUE HACER CON EL INDIO? UN ANALISIS DE LAS OBRAS DE FRANZ TAMAYO Y ALCIDES ARGUEDAS
}

\author{
POR
}

MARTA IRUROZQUI VICTORIANO

\section{INTRODUCCIÓN}

El presente trabajo analiza las soluciones que proponen las obras de Alcides Arguedas, Pueblo Enfermo y Raza de Bronce, y de Franz Tamayo, Creación de la Pedagogía Nacional al problema indígena y a la relación que existe entre el indio y el mestizo (1) respecto a la cuestión electoral. Ambos aspectos conllevan al mismo tiempo una discusión sobre la conversión de Bolivia en un Estado-nación moderno cuya trasfondo es, en realidad, encubrir una competencia en el interior de la élite (2) por controlar el poder político (3) a principios del siglo XX. El estudio de las cuestiones aludidas se realiza en dos niveles, mientras el primero ofrece una perspectiva general sobre el debate acerca de qué hacer con el indio, el segundo se refiere a las soluciones que le dan ambos autores, relacionándolas con un proyecto intelectual

(AME90-0849-CO2-01) Proyecto Plan Nacional I + D.

(1) No se pretende una definición clasificatoria de las categorías indio y mestizo. Ambos términos son entendidos como bloques cerrados que si bien hacen mención a realidades muy complejas pueden sintetizarse segun el valor que Franz Tamayo y Alcides Arguedas les dan. Por tanto, indio será sinónimo de campesino comunario vinculado a una hacienda del Altiplano y mestizo equivalente a cholo urbano de extracción social baja, migrante desarraigado del campo y con aspiraciones a formar parte de la vida política del país a través de la Administración Pública.

(2) Se trata de un concepto englobador de aquellos sectores sociales que poseen poder político y económico y de aquellos otros que constituyen su margen de reclutamiento y reserva. Cuando se habla de élite se hace referencia a grupos heterogéneos, aún no consolidados como clase aunque compartan una herencia corporativa. Son grupos de poder diversificado que se extienden en todos los aspectos del proceso de desarrollo y que gestionan intereses muy variados.

(3) A este respecto resulta interesante el trabajo de Deborah A. Poote, "Ciencia, peligrosidad y represión en la criminología indigenista peruana" en Charles WALKer y Carlos AciutrRe. (comp.), Bandoleros, abigeos y monioneros. Criminalidad y violencia en el Perí, siglos XVII-XX. Lima, Instituto de apoyo agrario, 1990. 
de participación política. Dicho proyecto, a su vez, está inserto y responde a los imperativos elitistas de perpetuación del orden establecido a través del cambio controlado.

Los textos citados encarnan las preocupaciones de un período de debates sobre cuestiones nacionales iniciado por Rigoberto Paredes con la Política Parlamentaria de Bolivia (1908) y desarrollado después por Armando Chirveches, La candidatura de Rojas (1908), Tejada Sorzano, Después de la Crisis (1909) y Bautista Saavedra La Democracia en nuestra Historia (1921). En 1909 se publica Pueblo enfermo y en 1910 Creación de la pedagogía nacional. El primero pretendía curar las enfermedades sociales con ayuda de la ciencia positivista y el segundo proponía reorganizar el país de acuerdo con exigencias vitalistas. El resultado de este último planteamiento es una tesis geo-socio-antropológica en torno al problema de la creación de una ideología basada en el carácter nacional. Se proponía "disociar científicamente, y por medio de una crítica comprensiva, todos los elementos raciales de que consta nuestra naturaleza de bolivianos, para deducir métodos y leyes integrales sobre qué fundar una pedagogía nacional» (4). Por su parte, Pueblo Enfermo es una crítica global de la sociedad y la política boliviana construida a partir de la denuncia de la decadencia de la raza, la corrupción política y el atraso cultural, "y es ahora que en este libro encontrarán los bolivianos la explicación de nuestra actual desgracia y hallarán lecciones de energía los jóvenes» (5). A pesar de la trascendencia que tuvieron ambos ensayos en la definición de los términos de la coexistencia de los distintos grupos sociales y étnicos, su debate no empezó ni concluyó con ellos, aunque sí quedó resumido como referencia común en la conformación ideológica de los partidos políticos. Por su parte, Raza de Bronce (1919) refuerza las argumentaciones de este texto al contrario de lo que señalan quienes quieren ver en él un cuadro invertido de lo expuesto en Pueblo Enfermo (6). En Raza de Bronce se ejemplifican las afirmaciones del texto anterior a través de una historia que describe la opresión del indio, el autoritarismo mestizo y la decadencia blanca, paralelamente a la usurpación de las tierras de los indios y su esclavitud en las haciendas, al establecimiento de un sistema

(4) Franz Tamayo, Creación de la pedagogia nacional. La Paz, Ed. Juventud, 1986, pág. 14.

(5) Alcides Arguedas, Pueblo Enfermo, La Paz, Ed. Juventud, 1988, pág. X.

(6) Juan Albarracín Millán, El gran debate, La Paz, Ed. Universo, 1978, pág. 154. 
despótico de privilegios patronales y al desconocimiento de los derechos humanos en los sectores populares.

Aunque discrepaban en los principios y los procedimientos, los dos trabajos intentaban enjuiciar y resolver una misma realidad, y al hacerlo expresaron no sólo las tensiones ideológicas de las divergencias políticas liberales sino la preocupación de un sector de la élite por la irresolución de la cuestión nacional. Y esta preocupación en vez de referirse al desinterés de su propio grupo social se sintetizó en una disconformidad con el atraso y una invocación exagerada al progreso. Pero su ausencia en ningún momento estuvo referida de forma directa o fundamental a los móviles de la gestión política sino a otro tipo de consideraciones que se sintetizaron en el medio geográfico y la raza, sin implicar esta última situaciones de clase o de grupo. La geografía y los indios fueron la principal razón para la ausencia de una cultura boliviana y, por tanto, para la inexistencia de Bolivia como nación. De ahí el interés por debatir la cuestión indígena y por establecer su grado de influencia en las características del país cuyo drama social se debe a la insuficiencia de cultura para enfrentarse a las determinaciones del medio geográfico y la raza. Con ello no sólo desviaron las motivaciones de la élite sino que diseñaron mejores mecanismos de legitimación de la subordinación social.

\section{INDIOS CULPABLES E INDIOS INOCENTES. EL DEBATE SOBRE QUÉ HACER CON EL INDIO}

Terminada la Guerra Federal de 1899 y acallada la rebelión indígena, el debate sobre qué hacer con la población indígena se intensificó. Era necesario resolver el modo en que ésta debería ser gobernada con lo que se retomaba la discusión colonial acerca de su naturaleza y carácter. Las respuestas dadas manifestaron una confrontación entre los líderes políticos bolivianos, de manera que la multiplicidad de posiciones desencadenada por esa polémica terminó convirtiéndose en una de las piezas diferenciadoras de los partidos políticos. El acceso al poder de los distintos miembros de la élite quedó regulado según la postura que mantuviese cada partido con respecto al debate constitucional acerca de la política a seguir con el indio (7). Pero la presencia

(7) Marta Irurozoul, "Las élites bolivianas y la cuestión nacional". Ponencia presentada al Encuentro de Americanistas españoles, Instituto Ortega y Gasset, Madrid 1991. 
indígena en el debate nacional no obedecía a una preocupación real por su estado sino a la resolución de los problemas de competencia en el interior de la élite. Estos se paralizaron con la política que el Partido Liberal desarrolló a partir de la explotación de los miedos interiorizados de la población criolla-mestiza. El esfuerzo periodístico por magnificar la "guerra de castas», junto con la descripción de los factores ambientales y biológicos del indio reforzaron la enraizada cultura del terror y el carácter reaccionario de la sociedad a través de imágenes de indios sanguinarios en continuo acecho de la población blanca. Este pánico generalizado no sólo fue instrumentalizado por los miembros del partido liberal como amenaza frente a otras fracciones en pugna de la élite, sino que también evitó la formación de lazos de solidaridad horizontales de los indios con otros grupos sociales subalternos. Al hacerlos aparecer a través de la prensa y la literatura como delincuentes cargados de vicios ancestrales se construyó una barrera ideológica que los mostraba inadecuados y peligrosos para reivindicaciones futuras. El predominio de estos esquemas de percepción y apreciación reforzaron, por tanto e inevitablemente, el autoritarismo de los defensores ordinarios del orden establecido. Con esto se pretendía una tregua que estabilizase al país y condujera la pugna en el interior de la élite por los cauces constitucionales de un régimen de partidos políticos, además de que quedasen regulados los mecanismos de cooptación social.

Visto lo anterior, el debate sobre lo que se debería de hacer con los indios y la definición de su naturaleza tuvo dos variantes principales. La primera consistía en un alegato a favor de la criminalidad y brutalidad indígena. La civilización no había encontrado el modo de enseñar al indio a reprimir su naturaleza bestial $\mathrm{y}$, por tanto, eran los instintos naturales del sexo y la sobrevivencia los que regían su vida social. La otra opción discursiva catalogaba la subjetividad indígena como pasiva e inocente. El indio era un sujeto indefenso y necesitado de protección paternal ya que la explotación a que se había visto sometido durante el período colonial y republicano le había embrutecido y en consecuencia invalidado para tener acceso por sí mismo a la ciudadanía. La evolución pacífica del indio había sido constreñida por el colonialismo español y el poder terrateniente en la república cuyos abusos explicaban por qué éste no había llegado a un concepto claro de nación. Como solución se imponía la tutela del indigena pero no bajo el fundamento de la inferioridad de la 
raza sino obedeciendo a principios de igualdad social. Con ello se le reconocía que su marginación se debía a estar inferiormente colocado dentro de la actividad laboral del país y no a motivos raciales. En ambos casos la naturaleza indígena estaba modelada por el medio ambiente y alimentada por las pasiones humanas naturales que en primer caso se definían como inmorales y en el segundo como expresión de una justicia vengadora universal.

El desencadenante de las posiciones anteriores fueron los acontecimientos de Mohoza (8). A partir de ese momento la cuestión india se convirtió en el gran debate nacional y quedó reflejada en los periódicos de los dos modos ya descritos. Se insistió tanto en la amenaza y la lacra social que suponía la raza indígena así como en la necesidad que estos tenían de ser tutelados para su incorporación nacional. Aquellos que abogaban por su exterminio consideraban que debían de ser castigados por romper la ley y que en ningún caso tenían que ser idealizados por sus manifestaciones pasadas. Si se comportaban indebidamente debían ser tratados como criminales e incluso trasladados a las regiones gomeras del Beni donde al menos podrían ser puestos a trabajar para el progreso de la nación (9). Al mismo tiempo que tales posiciones eran difundidas se publicaban también planes más amplios para resolver el problema indígena sin llegar a los extremos antes propuestos. Un ejemplo de ello lo realizó Severino Campusano al diseñar un proyecto completo para la renovación del gobierno boliviano. Se recomendaban leyes y tribunales especiales para los indios ya que aunque no eran inferiores biológicamente sí lo eran culturalmente puesto que conservaban la mentalidad inca. En consecuencia Campusano dio gran énfasis a la importancia de una educación liberal y científica hasta el punto de proponer destinar los impuestos cobrados a los indios para construir escuelas en las comunidades (10). De acuerdo con el plan Campusano, a los indios debía de dárseles un lugar especial en la sociedad y luego, por medio de la educación, debía integrárseles poco a poco a la nación. Se trataba de restaurar una pacífica pero subordinada situación para los indios que por supuesto no

(8) La masacre de Mohoza consistió en la matanza de un batallón completo del partido liberal por parte de la población indigena que supuestamente apoyaba a este partido. Este suceso se hizo popular a través del juicio que se realizó contra los implicados en los hechos desde 1901 a 1904.

(9) El Imparcial, La Paz, 3 de mayo de 1898 y 12 de mayo de 1899. Hemeroteca de la UMSA.

(10) El Imparcial, La Paz, 1 de mayo de 1899. 
implicaba poner fin al proceso de exvinculación de tierras puesto en práctica por los partidos civilistas desde 1884 (11).

Fueron muchas las propuestas y contrapropuestas que se desarrollaron por parte de uno $u$ otro sector, $y$ sin tener en cuenta su calidad e intenciones, todas contribuyeron a mantener la imagen del indio contemporáneo en los debates de la identidad nacional boliviana a principios de siglo. En todo momento hubo interés por controlar la emergente imagen del indio y el discurso sobre el mismo. Parte de las causas de este comportamiento se reflejarán en las obras de Franz Tamayo y Alcides Arguedas, autores que no sólo tomaron parte en dicho debate a la vez que fueron modelados por el mismo, sino que sintetizaron y definieron del modo más polémico los esfuerzos por conocer, definir y normalizar la presencia de la población india en la comunidad nacional. Con la obra de ambos, el propósito de la élite boliviana en el gobierno vio redondeado su proyecto de reconstrucción como grupo sin tener que resolver las exigencias de conformación nacional vertidas por otros sectores sociales. Y esto sucedió porque en dicho debate el sujeto o la causa que explicaba las deficiencias y características de Bolivia era ahora el indio. Esa discusión sobre qué hacer con él pretendía entretener el descontento e insatisfacción de aquellos bolivianos que pedían un proyecto hegemónico de construcción de una nueva identidad o comunidad nacional, tal como se había expresado en los programas del Partido Liberal. El desinterés que la élite manifestaba por ese propósito quedó encubierto por una interpretación del indio como el principal obstáculo para que tales anhelos se materializaran. Si no se producía el progreso ni la modernización de Bolivia era sobre todo porque existía un sustrato de población incapaz por sí mismo de adaptarse a los imperativos de un país competitivo a nivel internacional. De ahí que la discusión entre indio criminal e indio víctima se reprodujera sin perder actualidad. Mientras la élite necesitase trasladar la renta del país a su propia reproducción y uno de sus mecanismos fuese la apropiación de tierras en el Altiplano, la polémica indígena estaría presente bien para justificar los actos de los grupos dominantes, o bien para reubicar al indio en actividades laborales que disminuyeran su amenaza y le tornaran productivo al proyecto de reconstrucción de la élite.

De las corrientes de opinión expuestas, Franz Tamayo y Alci-

(11) Erwin P. Grieshaber, "Resistencia indígena a la venta de tierras comunales en el Departamento de La Paz". DATA, n 1, La Paz, INDEAA, 1991, pág. 134. 
des Arguedas pertenecen a aquella que esboza un programa de reivindicación cultural basado en un conocimento sistemático de la cultura, la sociedad, el comportamiento y la explotación indígenas. Pero dicha reivindicación estará referida a la imagen de un indio amorfo y pasivo que necesita que alguien hable por él y le represente. Su estatus social y moral deberá ser creado y constituido por los intelectuales, quienes se consideran sus portavoces a la vez que los únicos capacitados para tener una visión acertada de una nueva comunidad moral boliviana. Pero para probarlo se necesitaba un estudio clínico y disciplinado de las fuerzas objetivas causantes del comportamiento indígena. Una clasificación científica basada en el ambiente social, la higiene, los sentimientos morales e inclusive el patriotismo haría posible el control y la eliminación de las causas ambientales y fisiológicas que dan lugar a un comportamiento criminal. Se inicia, por tanto, el compromiso no sólo de defender sino sobre todo de crear al indio como sujeto legal y tipo étnico básico, hecho que anula la noción de cultura nacional como un diálogo entre iguales. Esta unidad discursiva paternalista especulaba con las posibilidades del indio en un Estado-nación moderno sin considerar seriamente su participación en calidad de ciudadano. De ahí que el carácter de la reivindicación histórica y cultural implicara una reforma educativa previa que explicitase la función laboral y social de los indígenas. Su instrucción se privilegió como uno de los aspectos centrales de su reivindicación cultural y política y, también, como el más adecuado para llevar a cabo su integración al tiempo que su reforma y la de la sociedad que supuestamente oprimía al indígena. Su denuncia más que ser un ataque real a los privilegios criollo-mestizos justificó el proteccionismo de los proyectos educativos de manera que estos se hiciesen en nombre de los indígenas pero no por ellos mismos. En consecuencia, el desafío que creaba la diferencia cultural india a las entonces prevalecientes nociones de nacionalidad y comunidad nacional fue canalizado hacia el terreno de la reforma educativa y mili$\operatorname{tar}(12)$. Esta proporcionaba un terreno sobre el que los intelectuales podían desafiar las formas en las que el Estado había construido sus registros y normas de ciudadanía. Pero las refor-

(12) Sobre la militarización del indio: “... tanto en la campaña del 79, así como durante nuestras vergonzosas contiendas fatricidas, no se ha pensado ni remotamente en utilizar sus servicios (...) Probado está que las indiadas moralizadas y bien dirigidas, morigeran su carácter, demuestran indole apacible y cumplen con los deberes que se les imponen". El Comercio de Bolivia, La Paz, 20 de mayo de 1900. 
mas propuestas no se reducían a una crítica de la política gubernamental, más bien su valor residía en que representaban formas de comunidad y tradición pertenecientes a las distintas variedades de la élite. La pugna política dejaba así el campo de batalla para expresar su opinión a partir del qué hacer con los sectores subalternos. Su reforma y adaptación a una nueva sociedad equivalía a un alegato de los desposeídos de la élite a su derecho de ostentar el poder. Y una prueba de que es la lucha entre élites uno de los fundamentos finales del interés intelectual por el indio se apoya en que las soluciones que se dan al problema no consisten en elevar su nivel educativo y cultural al nivel del ciudadano criollo-mestizo, sino en ubicarle como trabajador. Por esta razón también se expone la necesidad de protegerles a través de la preservación de su separada situación cultural y jurídica dentro de la comunidad nacional ciudadana. El indio puede contribuir al desarrollo económico, al progreso moral y al nacionalismo boliviano sólo bajo estrictas y científicamente desarrolladas leyes de tutelaje, protección y preservación.

\section{LOS INDIOS Y LA CUESTIÓN NACIONAL EN LAS OBRAS DE ALCIDES ARGUEDAS Y FRANZ TAMAYO}

Tanto Pueblo Enfermo y Raza de Bronce como la Creación de una Pedagogía Nacional son un ejemplo de las afirmaciones antes expuestas. Ambos autores intentaron erradicar falsas imágenes sobre el indio-campesino a fin de distender los miedos interiorizados de la mancomunidad criollo-mestiza. Pero no significaba abandonar sus presunciones respecto a la naturaleza de la diferencia cultural y social, la determinación del cambio histórico, y la relación entre carácter cultural y medio ambiente. Pueblo Enfermo fue publicado en 1909 y Creación de una Pedagogía Nacional en 1910, es decir, los dos textos no fueron editados en el mayor momento de efervescencia de las rebeliones indígenas e invasiones de tierras como sucedió en las décadas del 1880 y 1890 , sino en un período en el que aún se respiraban las consecuencias que tuvo para los indios la guerra de 1899 y su alianza con el Partido Liberal. La lejanía por diez años de ese momento permitía la defensa del indio y el reconocimiento de su marginación frente al fracaso de los juicios promovidos por indígenas ante las iniciativas de expropiaciones de tierras por parte de los 
terratenientes criollo-mestizos (13) y la escasez de sus movilizaciones (14). Se trata de un momento en que comienza a intuirse un cierto cansancio y desencanto campesino frente a la ausencia de respuestas que suavicen su situación y, por tanto, un momento adecuado para poner en marcha planes que si bien no responden a los requerimientos indios sí suponen una promesa de atenderles como ciudadanos y ubicarles como tales. De este modo se pretende cortar una nueva explosión de las demandas indias pero esta vez con soluciones que resuelvan de modo más eficaz la situación de desasosiego y amenaza potencial que se vive en el campo. No se trata de solucionar el problema indígena, sino de quitarle su connotación de peligro, de aprovechar las cualidades de su trabajo en beneficio de la nación pero de una forma en la que los mismos indios encuentren acomodo para así disuadirlos de sus requerimientos. Ese qué hacer con los indios se convierte en la búsqueda de soluciones que los tornen en mano de obra pacífica y útil al esfuerzo de reconstrucción oligárquica.

De las muchas propuestas destinadas a resolver el problema indígena la que contiene un mayor grado de seriedad es la llamada reforma de la educación. Puesto que se parte de la consideración de que el indio es constitutivamente diferente de los otros ciudadanos más evolucionados a causa de su explotación, se sustenta también que carece en principio de la conciencia moral necesaria para el desarrollo de su libre albedrío y, por tanto, necesita tutela. Esto garantizaría su protección contra los peligros de una rápida evolución de los mismos hacia la ciudadanía, de la demagogia o fraccionalismo político y de los abusos de los terratenientes donde se incubaban «la atmósfera ingrata del odio real y de facto desprecio en que el colono español y el blanco republicano han envuelto y envuelven a la raza» (15). Además de esta manera también la nación boliviana se protegería de las particulares formas de pasión, sentimiento y peligrosidad inherentes a la psicología indígena. Una vez solucionado esos inconvenientes los indios podrían ser transformados en ciudadanos productivos, integrados en la economía capitalista y purgados de su distinción cultural. Pero para todo ello era necesario mejorar la imagen del indio ante la opinión pública y hacerlo de un

(13) Erwin GrIeShABER, "Resistencia indigena a la venta de tierras comunales en el Departamento de La Paz". Data, n 1, La Paz, INDEAA, 1991.

(14) Silvia Rivera CuSicaneui, "Rebelión e ideología: lucha del campesinado aymara del Altiplano boliviano, 1910-1920", en Historia boliviana, nos 1-2, Cochabamba, 1981.

(15) TAMAYO, [4], pág. 61. 
modo que no afectara a la obra de reestructuración de la élite llevada a cabo por el Partido Liberal. Las obras de Arguedas y Tamayo sintetizan este esfuerzo y lo vinculan al problema de cómo construir una futura nación boliviana. El resultado será el reconocimiento del mestizo como la base de la nueva comunidad moral al considerársele híbrido de las culturas europeas y andina.

Visto lo anterior, el resto del trabajo aborda en detalle las concepciones que Arguedas y Tamayo desarrollan respecto al indio. Para ello es necesario resaltar la vinculación de este tema con la cuestión nacional, las críticas gubernamentales y la capacidad electoral de los mestizos. La interacción de estos factores ayudará a definir la importancia, significado y alcance del problema indígena en el debate nacional.

\section{1. Sobre el indio}

Nataniel Aguirre a propósito de los males de la nación decía en la Asamblea Constituyente de 1871:

"¿A qué atribuir este fenómeno irregular? ¿Cómo salir de este espantoso círculo a que parece condenado por el destino? La causa, ¿está en los vicios de nuestra educación?, ¿está en nuestra índole, en nuestra raza, en nuestra sangre, en fin, como pretenden algunos? ¿O está en nuestras difíciles condiciones topográficas que se oponen al desarrollo de la industria, a la expansión de nuestras facultades...?, ¡Ah! señores diputados, permitidme deciros que hay algo de todo eso" (16)

Este discurso expresaba la necesidad de dar respuesta a la exigencia de algunos sectores sociales de conformar Bolivia como un Estado regional y étnicamente integrado. Tal preocupación se mantuvo en las décadas siguientes y se manejó a nivel de discurso para definir el grado de patriotismo presente en cada uno de los partidos políticos que luchaban por la presidencia de la República. Si con la Guerra del Pacífico (1879-1882) se inició la denuncia sistemática del militarismo, con la Guerra Federal de 1899 se acrecentó su discusión relacionándola con el tipo de gobierno más adecuado para las características raciales y geográficas del país. Terminada la guerra civil las promesas hechas por el Partido Liberal en cuanto a dar respuesta a las necesidades

(16) Nataniel Aguirre, Redactor del Congreso Nacional, 1871.

\section{R. I., 1992, now 195/196}


nacionales de los distintos grupos sociales quedaron en suspenso y una vez establecida La Paz como sede de gobierno, la polémica sobre el federalismo fue relegada a la oposición política dentro del mismo Partido Liberal. Las estrategias que desarrolló éste a raíz de la participación indígena en el conflicto crearon un clima de estabilidad política adecuado para que la élite paceña realizara su proyecto de reconstrucción como grupo social dominante. Pero este hecho si bien no impidió que la cuestión nacional siguiese viéndose como inconclusa, sí evitó que se involucrase al gobierno y a los grupos que lo sostenían en su resolución. En su lugar se colocaron al medio geográfico y la raza y en torno a estos dos aspectos se construyeron las propuestas sobre una Bolivia con éxito y competente a nivel internacional.

La búsqueda de razones que explicasen por qué Bolivia no había podido conformarse como un Estado-nación conllevaba la existencia de disconformidad con el clima social y político de principios de siglo. Pero tal disconformidad no iba dirigida al sustrato gobernante, sino contra los sectores más marginales del país a quienes se culpó de ser el mayor impedimento para el progreso de Bolivia ya que el Estado-nación era un objeto al servicio de ese progreso. Las obras de Tamayo y Arguedas mantienen ese punto de vista, con lo que a pesar de algunas críticas al primer gobierno de Ismael Montes (1904-1909), no sólo aceptaron el clima creado por la élite liberal, sino que lo reforzaron. Ambos dieron validez a los argumentos sobre la incidencia del factor raza en toda esta problemática y por tanto terminaron reforzando la legitimidad del régimen liberal. Este, a través del problema indígena, vio convertidos en sus aliados a los mismos grupos que cuestionaban su poder a la vez que todos hicieron causa común contra el indio, quedando la política liberal refrendada por quienes la sufrían. La crítica intelectual lo confirmó y al hacerlo liberó a la élite de las preocupaciones nacionales. Estas recayeron desde entonces sobre indios y mestizos, y a partir de ellos se intentaron comprender las causas del supuesto fracaso nacional boliviano. Como éstas residían en la geografía y en la raza la mejor solución que se presentó fue plantear la reforma de la instrucción pública. Tampoco debe olvidarse que lo que buscaban en última instancia los dos escritores era una solución de gobierno, como lo especificó Tamayo: 
«no se desconozca nunca la idea maestra de todas nuestras especulaciones sobre esta materia. Esta idea es gobernar (...) lo primordial y fundamental es gobernar» (17).

Ambos pretendían dar salida a ese problema pero lo hicieron desde distintas posiciones políticas. Franz Tamayo era un incondicional de la política del presidente Montes (18) porque para él «... en cinco años ha hecho por la instrucción pública lo que todos los pedantes no harán seguramente en cincuenta, resolviendo otras tantas veces la legislación y la reglamentación del ramo. Ahí están las cifras de la instrucción primaria al final del gran quinquenio (...). Fue el presidente Montes quien comprendió el primero la necesidad de crear la instrucción primaria del indio (escuelas rurales) y a la vez de comenzar a hacer positivas las garantías constitucionales respecto al mismo" (19). Por su parte, Arguedas mantuvo una actitud más crítica y disconforme con el mismo gobierno, que expresaba a nivel político su desconfianza en la capacidad creativa de la población boliviana. Pero su inconformismo no se concretó tampoco en un ataque antigubernamental sino que redujo los problemas del poder a una cuestión étnica en vez de política. Para él ningún miembro de la sociedad resultaba válido en su estado presente: ni el indio, porque como miembro de una raza vencida, era servil, pasivo, sumiso; ni el blanco porque era arrogante, brutal, déspota, empleomaníaco, palaciego, etc.; ni el mestizo ya que era la mezcla pervertida de estas razas. Todos los bolivianos tenían los vicios de sus progenitores y no mostraban ninguna de sus virtudes (20). Ninguno servía sin ser sometido antes a una reforma moral porque para llegar al progreso era necesario «ilustrarse, aprender y enrique-

(17) Tamayo [4], pág. 16.

(18) A su regreso de Alemania, Tamayo abrazó el montismo que era el sector fuerte del Partido Liberal. A pesar del apoyo a las posiciones de Ismael Montes, no obtuvo los éxitos ni apoyos políticos esperados. Ante este rechazo funda la Liga Radical (1912) y posteriormente el Partido Radical (1915) con Tomás Manuel Elio, Luis Espinoza y Saravia, Cleto Cabrera García, etc. Después de años de desafortunada actividad política en la que unas veces estaba junto a los liberales y otra junto a los republicanos, terminará apoyando a Daniel Salamanca, quién en plena guerra del Chaco le hará ganar las elecciones presidenciales, elecciones que no le condujeron finalmente a la presidencia ya que fue identificado con las divergencias del presidente Salamanca con el ejército. Véase Juan AlBarracín Millán, El gran debate. Positivismo e irracionalismo en el estudio de la sociedad boliviana, La Paz, Ed. Universo, 1978, págs. 180-81.

(19) Tamayo [4], págs. 48 y 63.

(20) Albarracín [6], pág 53. 
cerse» (21). A pesar de que no anulaba sino simplemente dificultaba la posibilidad anterior, el indio terminó de una u otra forma siendo el causante de los rasgos negativos ya señalados por su radical oposición cultural a lo europeo, «nuestros pueblos hispanoamericanos no pueden ofrecer los mismos caracteres de perdurable firmeza que los del occidente europeo, porque aparte su reciente formación, que es un obstáculo a todo desarrollo, sus primitivos elementos étnicos estaban muy lejos de encontrarse aptos y adaptables a las nuevas condiciones de cultura y civilización que se les exigía" (22). No es que se negara la posibilidad de Bolivia como un Estado-nación moderno, sino que al insistir en el atraso de los indios, Arguedas buscaba legitimar sin oposición cualquier tipo de medida arbitraria respecto a ellos: "graves males provenientes, en primer término de desgraciados atavismos $\mathrm{y}$, en segundo, de una educación defectuosa e incompleta, o mejor, de la absoluta falta de educación, y para explicar este estado y como legítimo alegato en abono del relativo malestar del país, hay que insistir en declarar que es profundo el desacuerdo existente entre el territorio y la calidad de su población. Los elementos étnicos que en el país vegetan son absolutamente heterogéneos y hasta antagónicos. No hay entre ellos esa estabilidad y armonía que exige todo progreso, pudiendo decirse que aún está en germen el carácter nacional propiamente dicho, y, por lo tanto, no se siente animado de impulso consciente, capaz de engendrar un movimiento de actividad creadora" (23). Los indios tenían que someterse, en consecuencia, a una instrucción elaborada en su nombre y no por ellos mismos, a una instrucción encabezada por un grupo de intelectuales que vio en ésta una oportunidad de expresión y de ubicación política. Al dejarles el monopolio del discurso educativo el gobierno estaba distrayendo la presión de la competencia al tiempo que se liberaba de toda responsabilidad nacional. Por otra parte, también se consiguió un rediseño del indio según las necesidades de la clase dominante:

"¿Qué se debe hacer del indio? Su tradición y su natural inclinación le llaman hacia la tierra. Será siempre un agricultor de buena voluntad, mucho más si llega a conocer los modernos procedimientos. La fortaleza de su cuerpo lo capacita para ser un excelente minero. Su gran sentido de régimen y de disciplina,

(21) ARguedas, [5], pág. 71.

(22) Ibidem., pág. VII.

(23) Ibidem., pág. 31. 
su profunda e incomparable moralidad hacen del indio un soldado ideal, probablemente como no existe superior en Europa. Soldado, minero, labrador, esto es ya el indio, y lo es de manera inmejorable, en cuanto puede serlo alguien que lo ignora todo, y de quien nadie se cura, sino para explotarle. Una educación sabia debería desarrollar estos tres tipos de indio" (24).

Así, en el esquema social propuesto el indio jugaba un contradictorio papel social. Unas veces aparecía como una raza envilecida, y otras, como una promesa del robustecimiento de la nación. Pero veamos más despacio cómo cada uno de los autores analizados propone solucionar el problema nacional y el uso que hace del indio en este proceso.

Para Franz Tamayo hay que estudiar el alma "de nuestra raza, que es trabajo de verdadera creación", y, a partir de ella, tratar "de crear el carácter nacional que seguramente es en todo diferente al europeo" (25). Para esto es necesario despertar la conciencia nacional que equivale a despertar las energías de la raza, y esta energía es «lo que no se puede plagiar jamás y lo que justamente creemos que existe en nuestras venas» (26). Con estas afirmaciones se opone a aquellos que niegan que un grupo producto de diferentes elementos étnicos pueda tener un carácter nacional y una ley biológica propia. En contrapartida tiene que demostrar la validez de los elementos étnicos del país, y como el indio es el depositario de la energía nacional, gran parte de su propuesta está encaminada a hacer de él un factor de progreso: "civilizar al indio significaría el despertar de la raza y la reposición de las cosas" (27). El indio demuestra su potencial capacidad nacional al manifestarse autodidácto, autónomo y fuerte a pesar de su depresión histórica, de su indignidad social, de su pobreza, de su aislamiento, y de la hostilidad del blanco. Es el único que se "toma en serio la tarea humana por excelencia: producir, producir incesantemente en cualquier forma, ya sea labor agrícola o minera, ya sea trabajo rústico o servicio manual dentro de la economía urbana" y también es un factor de primer orden en aquellos momentos en que que la República entra en crisis y siente su estabilidad amenazada militarmente. De ahí que se defienda su participación en las funciones de la cosa pública y se condene su exclusión en ella bajo la excusa de la falta de conoci-

(24) TAMAYO [4], págs. 181-82.

(25) Ibid., pág. 8-9.

(26) Ibid., pág. 47.

(27) Ibid., pág. 58. 
mientos en que se mantiene el indio. Para que este argumento resulte inválido es necesaria la reforma de la instrucción primaria que implica "una cuestión más trascendente, tal vez porque se refiera a la formación de la nacionalidad misma: la difusión de la lengua española entre los indios», es decir, "la hispanización de lo indio" (28). Y esto supone la reeducación de quienes gobiernan ya sea en un sentido estatal como social, "se trata de educar a todos los que por ley, por la sangre, por la educación, por las costumbres y a veces por la sóla casualidad, están por encima del indio autóctono" (29). Con esto no se pretende remover ninguna estructura social sino favorecer una situación en que la hostilidad del india sea benigna y útil al desarrollo del país. El empleo de nuevos criterios sociales y étnicos para rehacer una nación que no es tal insiste en un reacomodo de los grupos dominantes, con lo que en cierta forma se está pidiendo una nueva redistribución del poder en el interior de la élite. Y en este reordenanmiento los intelectuales piden presencia política a través del monopolio del carácter del indio y unas soluciones para su conversión en ciudadano provechoso. Son ellos quienes establecen no sólo el modo para hacerlo sino los agentes que tiene que llevarlo a cabo. La instrucción primaria es el primer paso que debe dar el indio en su incorporación en la comunidad nacional, pero no debe de darlo si previamente no se ha producido una reforma de ésta ya que de no ocurrir así el indio pierde gran parte de sus virtudes fundamentales: «letrándose», se desmoraliza y se corrompe y "de honesto labrador o minero pretende ser ya empleado público, es decir, parásito nacional» (30). La instrucción pública puede contribuir indirectamente a menoscabar ciertas cualidades del carácter y del valor moral en el indio, y hacerle perder costumbres y concepciones que son "garantía de la vida y resorte de bienestarn. Al aproximarse al cholo y al blanco pierde parte de sus buenas costumbres y adquiere casi todos sus defectos. Por ello es imprescindible disminuir el contacto entre el indio y el mestizo hasta que este último no haya sido también sometido a una enseñanza reformada que anule sus vicios de carácter social y político y que le habilite para aprovecharse de las ventajas que comporta "una letradura sagaz y oportuna» (31). Se necesita comenzar reeducando a los blancos, después a los

(28) Ibid., pág. 64.

(29) Ibid., pág. 66.

(30) Ibid., pág. 69-70.

(31) Ibid., pág. 88. 
mestizos y más tarde a los indios para que así estos no sufran el "veneno moral» que significa su contacto.

Para Tamayo el mestizo es el elemento numérica y cualitativamente superior de la raza, y lo es gracias a que «siente en sus venas la sangre india invencida e invencible», la sangre de los depositarios de la energía nacional. Pero el indio sólo aporta al mestizaje moralidad y costumbre ya que, por sus condiciones sociales económicas y educativas, no piensa. De este modo, el mal de la pedagogía india no reside en él sino está en "los que nos llamamos y somos de hecho los directores y gobernantes de toda la vida nacional», es decir, en los intelectuales que ofrecen un programa de construcción nacional que les permita un lugar en la dirección del país. A partir de esto, condena por igual a indios y blancos y transfiere al mestizo la legitimidad del boliviano. De ahí que se insista en que el fundamento de la resurrección nacional está en la reeducación de los grupos superiores para que a su vez, éstos lleven a cabo "una sólida educación de su gran fondo étnico, esto es, los indios» (32). Sólo entonces el indio podrá aproximarse al mestizo y al blanco y, por tanto, se dará el primer paso a «la verdadera grandeza nacional». En consecuencia, la instrucción del indio es el slogan de un sector social que pide presencia política y para lograrla muestra a modo de propaganda las cualidades laborales del indio. Se le define y se rescata su humanidad no porque se la reconozca sino porque ésta les permite un programa político reivindicativo que les hace presentes en las remodelaciones en el interior de la élite. El arma que emplean es saber obtener del indio todas sus ventajas como trabajador, pero esta mérito no les impide reconocerle como peligroso ante las vejaciones e injusticias que viene sufriendo. Es más, les interesa mantener también este imagen para así continuar manejando los miedos interiorizados por la mancomunidad criollo-mestiza en el mejor estilo del Partido Liberal, pero esta vez en su beneficio ya que representan un modo de control del indígena, esto es, la educación. La misión de la escuela es profundizar esta energía nacional y no diluirla en la blandura del intelectualismo. Con lo que si bien el problema indio es un problema real también lo es secundario, ya que únicamente se mantiene a nivel de discurso parlamentario que pretende el rediseño elitista de los que ostentan el poder. El indio es progreso y es también miedo, la propuesta intelectual en realidad no va

(32) Ibid., pág. 126-27. 
dirigida a qué hacer con el indio sino a qué hacer con quienes tienen su monopolio.

Frente a la interpretación de Tamayo, Arguedas considera al indígena como una rémora social. De no haber predominio de sangre india "desde el comienzo el país habría dado orientación consciente a su vida, adoptando toda clase de perfecciones en el orden material y moral y, estaría hoy en el mismo nivel que muchos pueblos más favorecidos por corrientes migratorias venidas del viejo continente» (33). Además, el indio no ha conservado nada de la civilización que poseía en tiempos de la conquista, y eso le hace incapaz como opción de futuro, al contrario de lo que expresa Tamayo, para quién el indio no es poderoso por lo que puede llegar a ser sino por lo que ha sido en el pasado y por lo que puede conservar de él en el presente. Es la causa de esa perennidad metafísica que, aún viviendo en la opresión, para Tamayo sigue siendo "el fondo más sólido y el elemento más fuerte de las nacionalidades que al presente contribuyen a construir".

En cambio, el paisaje del Altiplano en Arguedas se encuentra íntimamente unido a las características del comportamiento del indio. La conformación física de esta región le ha impreso rasgos duros en el carácter y constitución. Posee la dureza y aridez del yermo, y también sus contrastes:

«...porque es duro, rencoroso, egoísta, cruel, vengativo y desconfiado cuando odia. Sumiso y afectuoso cuando ama. Le falta voluntad, persistencia de ánimo y siente profundo aborrecimiento por todo lo que se le diferencia. Todo lo que personalmente no le atañe lo mira con la pasividad sumisa del bruto, y vive sin entusiasmos, sin anhelos, en quietismo meramente animal. Cuando se siente muy abrumado o se atacan sus mezquinos intereses, entonces protesta, se irrita y lucha con extraordinaria energía. Hoy en día, ignorante, maltratado, miserable es objeto de la explotación general y de la general antipatía. Cuando dicha explotación, en su forma agresiva y brutal, llega al colmo y los sufrimientos se extreman hasta el punto de que padecer más sale de las lindes de la humana obnegación, entonces el indio se levanta, olvida su manifiesta inferioridad, pierde el instinto de conservación, y oyendo a su alma repleta de odios, desfoga sus pasiones y roba, mata, asesina con saña atroz» (34).

(33) Argulidas [5], pág. 37.

(34) Ibid., pág. 45-49. 
Con estas palabras Alcides Arguedas inicia un aviso dirigido a las élites del Altiplano para que no pongan en peligro su situación de privilegio. De ahí que mantenga una postura contradictoria y ambivalente respecto al indio. Tan pronto lo considera una raza en decadencia e inhábil para aceptar el progreso moderno y sin ningún tipo de espíritu emprendedor, como exalta sus costumbres y explica su situación de servidumbre a partir de los abusos cometidos por "frailes, funcionarios públicos y patrones» (35). De ambas posturas, la segunda se relaciona de forma más directa con un esfuerzo de renovación en el interior de la élite a fin de asegurar su continuidad. La denuncia de la explotación indígena no tiene como fin su solución sino concientizar al grupo dominante de los peligros que corre su mantenimiento como tal si no toma una rápida solución frente al descontento de los sectores subalternos. El discurso sobre la defensa del indio y el ataque a los terratenientes critica los abusos de los patrones con el fin de que estos tomen una postura más enérgica y efectiva acerca de la modernización de sus propiedades. El aumento de la productividad y la mayor rentabilidad de las fincas son para Arguedas los instrumentos de lucha contra cualquier ataque contrahegemónico que ponga en duda la legitimidad de los que ostentan el poder. Pero para que la mejora agraria resulte efectiva es necesario disminuir la amenaza india a través de una limitación de los malos tratos. Por tanto, los alegatos a favor de los derechos de dicha población tienen como propósito reformar el comportamiento de los terratenientes de manera que no favorezca posibles rebeliones que podrían romper la estabilidad social y política. No se propone un cambio de orden sino un menor empleo de la fuerza laboral. Y eso explica por qué en el trasfondo de su discurso, el indio termine siendo culpable de su propia situación al permitir al terrateniente que le sobreexplote como fuerza de trabajo: "si se le dijese que el ferrocarril también sirve para transportar cosechas se reirían de que tal dijese, y con la socarronería innata en ellos, señalarían los lomos de los indios y sus asnos, y objetarían que no hay tren más barato ni más cómodo que éste, es decir, que el asno y el indio" (36). Los indios impiden la modernización y progreso de las haciendas al resultar tan fáciles de emplear, por lo tanto, se impone una defensa y crítica de la explotación que sufren a fín de evitar que los terratenientes no se esfuercen en la mejora de sus propiedades. El desarrollo

(35) Ibid., pág. 56.

(36) Ibid., pág. 56. 
del país está limitado por las ventajas que los indios ofrecen como mano de obra, en consecuencia es necesario denunciar su empleo para que la élite no vea constreñidas sus posibilidades de evolución. El fácil uso de la fuerza indígena no actua a la larga en favor del grupo privilegiado ya que la hostilidad que genera puede conformarse en una fuerza capaz de derrocarlo o por lo menos capaz de favorecer sus sustitución. Se temen las represalias del indio no porque puedan provocar el exterminio de la mancomunidad criolla-mestiza sino porque puedan dar a las contra-élites en ascenso la oportunidad de hacerse con el control del país. El indio es un factor de distorsión en el conflicto que sostienen las distintas élites por el monopolio del gobierno, su existencia misma provoca que se le quiera emplear en la definición del conficto entre éstas tal como ya ocurrió en 1899, y por tanto se hace imprescindible controlar su agresividad y encauzarla de modo ventajoso para el sector dominante. Por esta razón, si Arguedas lamenta el hecho de que los blancos no cumplan su responsabilidad de redimir a la raza india, lo hace porque considera que se están poniendo en peligro como grupo privilegiado. Así, la crítica de Arguedas no va dirigida tanto contra la servidumbre de los indios como contra los abusos que éstos sufren y que originan que se rebelen, retardando así la producción y el progreso del país. Y también al denunciar los excesos cometidos por los blancos está advirtiendo sobre las consecuencias que conllevan los sentimientos de odio en los indios en lugar de protestar por la brutalidad de su represión (37). Tales planteamientos quedan más claros en Raza de bronce porque a través de los conflictos surgidos en una hacienda del Altiplano ejemplifica las afirmaciones de Pueblo enfermo.

Raza de bronce está dividida en dos partes, el valle y el yermo. La primera contiene las vicisitudes que pasan un grupo de indios a los que el administrador de la hacienda a la que pertenecen les ha encargado la compra de granos en el valle. La segunda parte se centra en los problemas que surgen entre una comunidad indígena y el hacendado de quién dependen. Dado que es en esta segunda parte donde se puede estudiar mejor la interpretación que hace Arguedas de la relación indio-patrón, el resto del análisis sobre el trasfondo de su obra estará centrado únicamente en ella. Se trata de insistir en la idea de que la

(37) Efraín Kristal, Una visión urbana de los Andes. (jénesis y desarrollo del indigenismo en el Perí, 1848-1930. Lima, Instituto de apoyo agrário, 1991, pág. 26. 
defensa del indio es un aviso a una reestructuración de la élite con respecto a los grupos subalternos. Con esto no se invalidan los argumentos de quienes insisten en que dicho debate esconde el enfrentamiento entre una oligarquía exportadora y una oligarquía tradicional de hacendados (38), pero dado que estudios recientes sobre la oligarquía paceña insisten en la diversidad de inversiones y actividades que ésta llevó a cabo, la dicotomía latifundistas versus exportadores no queda tan clara (39). En consecuencia, tampoco se discute que el debate político de comienzos del siglo XIX girase alrededor del mejor uso que se podía hacer de la mano de obra india. Pero más que verlo en términos del enfrentamiento ya señalado sería conveniente examinarlo teniendo en cuenta que la regulación del trabajo indígena disminuía el peligro de su movilización. De esta manera, las contraélites en ascenso no tenían tan fácil el derrocamiento del gobierno, sobre todo porque su iniciativa en la discusión del problema indio les daba representatividad como activistas políticos sin que participasen realmente de la verdadera arena política.

La crítica de Raza de Bronce a los terratenientes no cuestiona la legitimidad de la explotación del indio sino la legitimidad de un grupo de hacendados que consiguieron este estatus a través de los favores del gobierno de Melgarejo, a quienes "premió concediendoles enormes extensiones de tierra comunitarias y pasando por alto su morosidad de deudores insolventes» (40). Este hecho manifiesta toda la corriente de propaganda antimilitarista y anticaudillista que sucedió en la Guerra del Pacífico y que se vincula al asentamiento del régimen de partidos políticos como vía más adecuada para resolver los problemas de circulación en el interior de la élite. Al mismo tiempo, se vincula el discurso sobre la defensa del indio con la guerra del Pacífico.

A partir de la novela de Arguedas, se pueden establecer dos críticas fundamentales a los terratenientes:

1. Son patrones ilegítimos no sólo porque obtuvieron las tierras durante el gobierno de Melgarejo sino porque no supieron hacerlas productivas, "arrancaron la tierra de su poder, para distribuirla, como gaje de vileza, entre las mancebas y paniagua-

(38) Ibid., pág. 25.

(39) Vease Silvia Rivera Cusicanoui, "La expansión del latifundio en el Altiplano boliviano: elementos para la caracterización de la oligarquia regional" en Avances, $\mathrm{n}^{0}$. 2, La Paz., 1978. Roberto LaURA, Constitución de la oligarguía de la Paz, 1870-1900. Tesis de Licenciatura de Sociología por la UMSA. La Paz, 1988.

(40) Alcides Arguedas, Raza de Bronce, Bogotá, Ed. La oveja negra, 1985, pág. 93. 
dos del mandón" (41), y "sólo tuvieron la habilidad de encontrar en el indio un producto valioso de fácil explotación y el talento de inventar nuevas cargas, sin osar ningún esfuerzo de modernización" (42). Esta hubiera eliminado la fuente de su ilegitimidad ya que si se cuestiona su origen es con un carácter retroactivo que quiere ver justificada la falta de progreso por los abusos del dictador. Como algunos terratenientes no mejoraron sus propiedades ni impidieron dar mayor cobertura de poder a la élite y favorecer su engrandecimiento, la sublevación indígena es una consecuencia lógica que tiene que enfrentar. Con esto no se apoya al indígena en sus revindicaciones, sino que éstas pueden servir para que el sector dominante en el agro tome conciencia de los peligros que corre su situación social si no introduce mejoras que estén en la linea del proyecto de reestructuración y reconversión en el interior de la élite. Pero en última instancia el indio es culpable por su docilidad y conformismo de la situación de opresión en la que vive y también lo es de la ausencia de progreso en las haciendas. La facilidad con que se somete a las múltiples prestaciones que aporta son la justificación que Arguedas da al inmovilismo de terrateniente: «el indio era para él menos que una cosa, y sólo servía para arar los campo, sembrar, recoger, transportar las cosechas en lomos de sus bestias a la ciudad, venderlas y entregarle el dinero" (43). Su presencia es un factor de retroceso que impide a éstos buscar otras formas de explotación de la tierra. Así, no se condena la utilización de la mano de obra sino el estado de ésta, "como las (las haciendas) habían recibido de las manos perezosas de sus ociosos padres» (44) y, por tanto, se está apelando a su reforma, reforma, que puede venir propiciada por un nuevo proyecto de educación que haga de los indios elementos productivos y anule su peligro potencial. La condena de los malos tratos al indígena no se contradice con que se les continúe considerando inferiores socialmente, lo que se pretende es que la élite tenga las mayores facilidades para concretar su continuidad y limitar la competencia de las contra-élites en ascenso que la desgasta constantemente.

2. Los terratenientes ocasionan la sublevación india al no cumplir con las obligaciones que se derivan del pacto de reciprocidad entre ellos y las comunidades indígenas, "quería el señor

(41) Ibid., pág. 91.

(42) Ibid., pág. 92.

(43) Ibid., pág. 171.

(44) Ibid., pág. 171 
Pantoja ganar la voluntad de los colonos, cada día más distante, realzando con su presencia la ceremonia; pero olvidó con malicia mandar los artículos indispensables en ese caso" (45). Con esto están permitiendo que los indios tengan razones para rebelarse $\mathrm{y}$, por tanto, poniendo en peligro todo el proyecto de reestructuración de la élite ya que el descontento indio puede ser instrumentalizado por aquellos que ansían el poder. Por otro lado, el incumplimiento del pacto cuestiona el mantenimiento del indio como tal al darle motivos para que deje su condición de comunario, «ellos no pedían gran cosa. Unicamente que se les dejase libres en sus casas y no se recargasen sus tradicionales obligaciones con exigencias de nuevos trabajos» (46). La readaptación de la población indígena a un estado más adecuado a los intereses de la élite no pretende alejarla de las supeditaciones que implica su continuidad en la categoría de indios. En ningún caso se trata de hacerlos ciudadanos, es más, se insiste en las desventajas que existen en un cambio de estatus a través de su conversión en mestizos. A este respecto es interesante detenerse en la boda de Agiali y Wata-Wara, protagonistas indios de la novela y desencadenantes de la sublevación con que termina.

Los rasgos de belleza y generosidad con que los describe el autor sintetizan la imagen ideal de un indio que ya no existe, de un indio de la mítica edad de oro incaica, es decir, de un indio capaz de enfrentar al patrón en la irrealidad, y, por lo tanto, un indio que no es amenaza en la vida cotidiana porque no existe. El hacendado real no tendría justificación en sus actos si actuase igual que Pantoja en novela, si maltratara indios virtuosos, pero como la mayoría no lo son, "las mujeres mostraban las polleras en desorden, desnudo el seno y las espaldas, desgarradas las carnes, abominables de abandono y de embriaguez", la crítica del comportamiento del hacendado se invalida en sí misma. Pero más que resaltar la contradicción entre indio mítico e indio actual, lo que el pasaje de la boda ofrece es un rechazo de la conversión del indio en mestizo. De Agiali dice: «iba vestido de cholo (...) y presentaba traza que a los ojos de sus paisanos era imponente y resultaba simplemente ridícula" y de Wata-Wara: «se presentó disfrazada de chola (...) era un adef esio consumado que provocaba risa cuando se la veía caminar encogida por la intolerable estrechez de los zapatos» (47). Se valora al indigena

(45) Ibid., pág. 177.

(46) Ibid., pág. 181.

(47) Ibid., pág. 163-64. 
en la medida en que permanece como tal y sólo así es posible reconocerle su grandeza. "y con la libertad de sus movimientos volvió a adquirir la gracia juvenil que tanta seducción daba a su lindísimo rostro" (48), de lo contrario es objeto de una burla encaminada a invalidar su ascenso social. Se busca no la modernización de la mano de obra ni su conversión en individuos socialmente blancos sino el cambio de aquellos modos de explotación tradicional que no resultan productivos. Un cambio radical de su condición podría conducir a un reordenamiento social ya que «el día que esos dos millones sepan leer, hojear códigos y redactar periódicos, ese día invocarán tus principios de justicia e igualdad, y en su nombre acabarán con la propiedad rústica y serán los amos» (49). Para evitarlo se utiliza la violencia, pero ésta engendra más rabia, "y se sometieron por el rigor, como las bestias; pero creció su odio hacia los blancos» (50), y lo que pretende el discurso de Arguedas es limitarla sin reducir la servidumbre india. Hay que mantenerla pero con la suficiente racionalidd para que la opresión no se sienta como tal y termine en una "guerra de castas". El miedo a un enfrentamiento blancoindio tal como se hizo propaganda durante, y a partir de, la Guerra Federal de 1899 se reactiva y aparece en la novela con la función de disculpar, e incluso justificar la crueldad del comportamiento del hacendado, "en apariencia son humildes porque lloran, se arrastran y besan la mano que les hiere; pero !hay de tí si te encuentran indefenso y débil!. Te comen vivo. No hay peor enemigo para el blanco, ni más cruel, ni más prevenido que el indio" (51). De este modo la crítica a terratenientes como Pantoja se contrae cuando está en peligro la propiedad y supremacías blancas, sirve como discurso político en un debate parlamentario en el que se repartan áreas de poder, pero no busca una transformación real de las condiciones bolivianas, ni siquiera de las nacionales. Hay descontento pero éste desaparece cuando la reivindicación a favor de los sectores menos privilegiados de la sociedad encuentra respuesta en ellos. Es entonces cuando se reduce el conflicto de la explotación del indio a uno de supervivencia blanca frente al peligro que éste supone.

Establecida la dimensión de la crítica de Arguedas a los ha-

(48) Ibid., pág. 164.

(49) Ibid., pág. 211.

(50) Ibid., pág. 124.

(51) Ibid., pág. 210. 
cendados, se puede establecer una imagen unificada de la subjetividad indígena sobre la que se pretende llevar a cabo su reforma:

1. El medio ambiente modela al indio. Las diferencias que acusa el indio frente a la población blanco-mestiza residen en las características del paisaje andino, así como en el ambiente social creado por los hacendados que le fuerza a buscar venganza a través de la violencia. No contando con la justicia del Estado, los indios recurren al homicidio para deshacerse del patrón que ha matado y mata a los suyos. Al mismo tiempo las cualidades telúricas del paisaje incrementan la crueldad de toda expresión social indígena.

2. La brutalidad del crimen indígena es debida a la violencia con que el ser humano actúa en medios sociales y ambientes extremos. En su estado puro el indio, como sus antepasados, ama la justicia y es culto y generoso, pero en la actualidad vive explotado por los terratenientes y sin posibilidades de obtener la justicia del Estado que haga frente a los abusos, con lo que tiene que recurrir a sus propios actos de venganza. El indio, entonces, retorna a un estado animal que lo invalida para obtener los atributos de ciudadano, y, por lo tanto se convierte en un ser al que se debe explotar o proteger. Como su violencia es resultado de un orden social que lo bestializa, la solución para hacerlo útil a las exigencias laborales es tutelarle por medio de una educación adecuada y no establecida por él.

En resumen, los indios son tratados de modo clemente y humanitario no porque se haya tomado conciencia de lo trágico de su explotación sino porque ellos ponen de manifiesto los peligros que puede traer una conducta irresponsable por parte de los hacendados. Las alusiones a su degeneración justifican y explican que no se les pueda dar la categoría de ciudadanos porque ya en nada se parecen a sus antecesores incas. Se valora al indio en el pasado, no en el presente porque se considera que a causa de los abusos que ha experimentado lo que queda de él es algo desvirtuado e imposible a retornar a un estado de grandeza que le permita ser considerado como un igual. Para que en un futuro esto pueda ser posible es necesario llevar primero una tarea de mejora del indígena. Pero en Raza de Bronce no se plantea el modo de su integración como sí sucede en Pueblo Enfermo, donde al igual que el texto de Tamayo se insiste en que el indio debería ser gradualmente integrado a la civilización moderna bajo la guía de gobernantes ilustrados que finalmente 
erradicarían cualquier rasgo de la cultura india en la nación moderna. Sin embargo, en ningún caso se abogaba por la reorganización de la nación boliviana a través de la reevaluación de su cultura precolombina, de manera que el pasado histórico indígena se convirtiese en la característica integral de una nación nueva, tal como sí ocurre en una de las modalidades del indigenismo peruano (52). Sólo se favorece una instrucción indígena que se base en un conocimiento disciplinado y sistemático del carácter del indio. Esto se esboza en un programa de reivindicación cultural que permite ver como los intelectuales bolivianos progresistas de principios del siglo XX estaban más preocupados por el estancamiento económico de su país y de las consecuencias que este podría tener en el ordenamiento de jerarquías sociales que por los abusos cometidos contra el indio. A pesar del discurso de comprensión hacia el, lo consideraban un estorbo, una barrera al progreso aún mayor que la oligarquía terrateniente tradicional. De ahí que se le terminara culpando del estado de atraso de Bolivia y se le negaran los atributos de ciudadano, hasta el punto de que el debate sobre qué hacer con el indio se redujo, en última instancia, a informar a un público urbano acerca de una realidad poco comprendida y a mostrarle la imagen de un indio que con su comportamiento confirma la supeditación en la que vive.

\subsection{Sobre el mestizo.}

"¿Qué hace el indio por el Estado?

Todo

¿Qué hace el Estado por el indio?

¡Nada!» (53)

El problema del mestizaje y del destino, funciones y cualidades del mestizo es ampliamente discutido en los textos trabajados, siendo incluso el tema que articula el debate sobre qué hacer con los indígenas. Por esta razón las reflexiones que se van a exponer aquí sobre él son únicamente las referidas a cómo, al contrario de lo manif estado en el discurso de ambos autores, se trata de evitar por un lado la conversión del indio en mestizo y por otra el control de la capacidad electoral de este último a

(52) Efraín KRISTAL, [37], pág. 27.

(53) Tamayo $|4|$, pág. 58 . 
través de la invalidación de lo indio. Todo ello en el marco de un conflicto entre élites que ven en la suspensión de las aptitudes de los grupos subalternos una oportunidad para concentrarse como grupo privilegiado.

Tanto en el ensayo de Arguedas como en el de Tamayo la importancia del indio queda desplazada por la del mestizo en el sentido de que si quiere sobrevivir tiene que mestizarse. La exigencia de misegenación aparece como el único medio del proceso de homogenización racial y transacción histórica entre la España conquistadora y la América india, pero este hecho no se interpreta como progreso social sino como solución a un duelo entre razas que está desgastando la definición nacional de Bolivia. De ahí que Tamayo insista en que al mestizo le está reservado el destino de ser la raza homogenizadora de la nación, y Arguedas admita que hasta el cholo puede llegar a cultivarse y ser un factor de progreso, siempre y cuando se de un proceso previo de aculturación de indios y mestizos. Pero estas intenciones se contradicen a la hora de enfrentarse al indio real y no a uno idílico transformado mediante la reforma educativa. A consecuencia de la ubicación geográfica de Bolivia, el elemento étnico no se renovó de manera que «los elementos dominantes de la raza, indios y cholos fueron desalojando paulatinamente, y no obstante los prejuicios de casta de las clases superiores, la poca sangre europea que quedó en los comienzos del siglo» (54). El indio invadió todas las esferas sociales, "y por lo mismo se nota cierta flojedad y decadencia en esas cualidades" (55). Al no existir renovación en los grupos étnicos componentes del país éste ha ido descendiendo en grado cultural, de tal manera que se puede afirmar que el origen del fracaso nacional de Bolivia, o mejor, de su retardada conformación reside en la presencia india. En la medida que se ha establecido intercambio con él se ha degenerado la raza blanca: "ha venido desplazando, sumergiendo y desnaturalizando el núcleo racial del elemento íbero, que, ahogado por el empuje incontenible de la masa mestiza, ha ido perdiendo sus cualidades para heredar las que la raza sometida, menos apta que la otra" (56). Se ha expandido el espíritu sumiso y avasallable de las "turbas» indígenas incapaces de guiar por sí mismas sus propios deseos, "y todo se ha ido acholando, aplebeyándose, ordinariezándose como todo se achola y se ordinarieza en Bolivia

(54) ARguedas [5], pág. 81.

(55) Ibid, pág. 106.

(56) Ibid., pág. 308. 
desde hace muchos lustros, o desde la colonia, en suma, pues, repito igualmente, es el mestizaje el fenómeno más visible en Bolivia, el más vasallador y el único que explica racionalmente y de manera satisfactoria su actual retroceso" (57). El odio de Arguedas al mestizo es en última instancia odio al indio, odio a que éste pueda transformarse en mestizo y aspirar a los derechos y privilegios del blanco-criollo. Mientras el indio permanece como tal es controlable ya sea mediante un discurso de exaltación de la cultura incaica o mediante otro que justifique su estado de penuria por su carácter criminal, pero en el momento que aspira a cambiar de posición y adquirir caracteres sociales mestizos se insiste en su invalidez, y por último se le acusa del retroceso nacional. De esta forma se anula también al mestizo como persona idónea para la dirección del país puesto que reúne todos los vicios que redundan en la decadencia de éste. Al calificarle de holgazán, perezoso y alcohólico se le está negando su presencia en diferentes encarnaciones, bien sea como gobernante, legislador, magistrado, industrial y hombre de empresa. Si al indio se le teme es porque puede llegar a cholo, y a éste se le rechaza porque es indio, "somos productos del pasado, porque nada engendra nada y las tendencias taradas se pagan» (58). $\mathrm{Y}$ este rechazo conlleva una negación a acomodar la realidad de la diferencia cultural dentro del país.

Frente a las posiciones de Arguedas, Tamayo rescata la utilidad del indio en un proyecto de progreso que de a la élite instrumentos para consolidarse. No se le rechaza, al contrario, se exalta su resignación, trabajo y «las admirables condiciones de sus costumbres, de su naturaleza física y moral que hacen de él uno de los factores humanos más ricos y considerables que puede ofrecer la historia» (59), con la idea de invertir el proceso del indio a cholo en de cholo a indio. Si Arguedas invalida al mestizo por tener sangre india, Tamayo lo valora por esa misma razón, pero no se trata de una valoración positiva sino de la causa que le sirve para justificar su necesidad de instrucción. De esta manera llega a la misma conclusión que Arguedas, es decir, a invalidar la capacidad electoral del cholo y por tanto a discutir su presencia política. Si para el primero «son los gobernantes cholos, con su manera especial de ser y de concebir el progreso quienes han retardado el movimiento de avance de la República,

(57) Ibid, pág. 328-377.

(58) Ibid., pág. 252.

(59) Tamayo |4], pág. 163. 
ya no únicamente en su aspecto institucional, sino también en sus factores económicos e industriales, de tan grande influencia en el mundo" (60), para el segundo el cholo no es un buen y sano elemento de orden ni de estabilidad social porque no contribuye con su esfuerzo individual al crecimiento del país. El parasitismo social de que se acusa al mestizo se complica con la pereza y, por tanto, se le hace aparecer como un individuo sin decisión ni opinión, "pasta fácil que se ha amoldado a las locuras y ambiciones de nuestros más viciosos demagogos» (61). Se le teme políticamente porque si bien no todos pueden votar sí participan activamente en ese campo a través de las clientelas, de ahí que exista una fuerte necesidad de descalificarlo declarándolo inconstante y de "espíritu ovejuno». Al declarar que las clases populares en Bolivia se apasionan sucesivamente por principios de contradicción, por caudillos que encarnan tendencias opuestas, y que de esta asociación nunca "consiguen ventaja alguna de ningún cambio político» a no ser dar "un poquito de lustre a esas entidades que se llaman partidos y a las cuales se honra en pertenecer, aunque desconociendo sus principios, porque no los tienen, o si los tienen, los violan los mismos que los proclaman" (62), se esta culpando al mestizo del mal funcionamiento del régimen de partidos políticos. La crítica al gobierno se realiza, entonces, mediante la crítica a la incapacidad de sus electores, con lo que en vez de cuestionar las estructuras de poder se está justificando la exclusión política de gran parte de la población boliviana. Esto con la pretensión de obtener un mayor control de las decisiones políticas por parte de la man comunidad criollo-mestiza y una disminución de las posibilidades de ascenso social de otros grupos.

A modo de conclusión, indios y mestizos sirven para dirimir el resultado de las competencias en el interior de la élite, pero son anulados en la medida que pueden conformar una oposición a ésta o formar parte de su plantel de reclutamiento. Sus demandas ponen en peligro los privilegios del grupo dominante por el hecho de pretender apropiarse de los títulos y formas que constituyen su singularidad. En vista de ello, los individuos comprometidos

\footnotetext{
(60) ARguedas, [5],pág. 81.

(61) TAMAYO [4], pág. 56.

(62) Arguedas [5], pág. 77.
} 
no pueden conservar su posición, su especificidad y su rango si no es a condición de la separación social con quienes les siguen inmediatamente en la jerarquía. De ahí la necesidad de lograr objetivamente la desvalorización de los pretendientes a sus privilegios. Esto lo obtienen mediante un régimen de partidos políticos cuya función es poner límites a la competencia, y con ello a las transformaciones de posición social que aquella no dejaría de ocasionar. Las reglas formales del sistema partidario sirven, por tanto, para proteger a la élite del exterior, y no tanto frente a los grupos subalternos como frente a otras fracciones de su misma clase o frente a los «advenedizos» de su propia fracción (63). Estos utilizan el desencanto indígena y mestizo y la amenaza de su movilización para iniciar una negociación y un reordenamiento de los privilegios sociales. Pero el descontento ante la política gubernamental se reduce si no a invalidar la categoría ciudadana de indios y mestizos sí a posponerla en espera de la mejora de sus condiciones intelectuales. De esta forma las exigencias de construcción nacional se diluyen en protestas étnicas que ven en la raza la causa del atraso boliviano. En consecuencia, en el discurso académico los sectores subalternos son los promotores de su propia marginación al dar razones que justifican y legitiman que sean otros grupos de la sociedad los encargados de dictaminar su papel social. Mediante un proyecto de reforma educativa que asegure un orden jerarquizado, se reduce la devaluación del prestigio social que sufririan las élites por la competencia de otros sectores. Esta estabilidad permite una cooptación social que no pone en peligro la reestructuración del bloque dominante. El discurso de reivindicación indígena es, por tanto, no sólo una plataforma sobre la que se establecen divisiones ideológicas entre los partidos políticos, sino también una forma de garantizar el orden existente.

(63) Pierre Bourdieu, La distinción, Madrid, Taurus, 1988. 